\title{
Acquired Factor X Deficiency in Light Chain Amyloidosis: A Report of 2 Korean Cases
}

\author{
Youngeun Ma, M.D. ${ }^{1}$, Eui-Hoon Kwon, M.T. ${ }^{1}$, Jung-Eun Lee, M.D. ${ }^{2}$, Kihyun Kim, M.D. ${ }^{2}$, Hee-Jin Kim, M.D. ${ }^{1}$, \\ and Sun-Hee Kim, M.D. ${ }^{1}$ \\ Departments of Laboratory Medicine \& Genetics ${ }^{1}$ and Medicine², Samsung Medical Center, Sungkyunkwan University School of Medicine, Seoul, Korea
}

\begin{abstract}
Amyloidosis is a heterogeneous group of diseases in which misfolding of extracellular proteins is the pathogenic factor. Light chain amyloidosis (AL) is the most common form of amyloidosis, and the causative proteins in AL are the immunoglobulin light chains produced by clonal plasma cells. Hemorrhagic events, ranging from mild subcutaneous hemorrhage to life-threatening bleeding, account for a significant proportion of morbidities and mortality in AL patients. Deficiency of factor X from deposition into amyloid fibrils has been reported to be the most common acquired factor deficiency in AL. We herein report 2 patients with acquired factor $\mathrm{X}$ deficiency in AL. A 55-yr-old woman with AL had a prolonged prothrombin time (PT) and an activated partial thromboplastin time (aPTT) of 2.51 International Normalized Ratio (INR) and $75.1 \mathrm{sec}$, respectively, which were corrected on mixing with normal plasma. Factor X activity was markedly decreased at 5\%. The other patient was a $67-y r-o l d ~ m a n$ with AL with a PT of 1.63 INR and an aPTT of $50.3 \mathrm{sec}$, which were corrected on mixing with normal plasma. Factor $X$ activity was decreased at $17 \%$. Neither of the patients had apparent hemorrhagic manifestations. Identification of acquired factor deficiency and timely coagulation tests are needed in the diagnostic workup and management in AL.
\end{abstract}

Key Words: Amyloidosis, Factor X deficiency, Korea

\section{INTRODUCTION}

Amyloidosis is a heterogeneous group of diseases in which misfolding of extracellular protein is the pathogenic factor. This process produces insoluble, toxic protein aggregates that are deposited in tissues in bundles of $\beta$-sheet fibrillar protein [1]. The most common cause of amyloidosis is clonal plasma cells in the bone marrow producing immunoglobulins that are amyloidogenic (light chain amyloidosis or AL) [2]. Hemorrhagic events, ranging from mild subcutaneous hemorrhage to life-threatening bleeding, account for a significant proportion of morbidities and mortality in

Received: November 18, 2010

Manuscript No: KJLM-10-159

Revision received: January 13, 2011

Accepted: March 2, 2011

Corresponding author: Hee-Jin Kim, M.D.

Department of Laboratory Medicine \& Genetics, Samsung Medical Center, Sungkyunkwan University School of Medicine, 50 Irwon-dong, Gangnam-gu, Seoul 135-710, Korea

Tel: +82-2-3410-2710, Fax: +82-2-3410-2719, E-mail: heejinkim@skku.edu

ISSN 1598-6535 (C) The Korean Society for Laboratory Medicine.

This is an Open Access article distributed under the terms of the Creative Commons Attribution Non-Commercial License (http://creativecommons.org/licenses/by-nc/3.0) which permits unrestricted non-commercial use, distribution, and reproduction in any medium, provided the original work is properly cited.
AL. Bleeding tendency is frequently encountered in AL, and while mild subcutaneous hemorrhage is the most common manifestation, life-threatening bleeding has also been reported [3-6]. Acquired hemostatic abnormalities, including coagulation factor deficiencies, hyperfibrinolysis, and platelet dysfunction are the background of bleeding tendency [5, 6]. In particular, acquired deficiency of factor $\mathrm{X}$ is the most common coagulation factor deficiency in patients with $\mathrm{AL}$, and it is postulated to occur via the adsorption of factor $\mathrm{X}$ to amyloid fibrils [3, 5-8]. We herein report 2 Korean patients with acquired factor $\mathrm{X}$ deficiency in association with AL.

\section{CASE REPORTS}

\section{Patient 1}

A 55-yr-old woman with generalized edema was diagnosed with AL on the basis of a renal biopsy. Serum and urine electrophoresis combined with immunofixation revealed M-protein of IgG/lambda type, and bone marrow analysis showed monoclonal proliferation of plasma cells. Coagulation tests revealed a prolonged prothrombin time (PT) of 2.51 International Normalized Ratio (INR) and an activated partial thromboplastin time (aPTT) of $75.1 \mathrm{sec}$ 
(29.1-41.9 sec). Thrombin time was within the normal range (18.6 sec; reference interval, 15.6-20.0 sec). Complete correction of the prolonged $\mathrm{PT}$ and $\mathrm{aPTT}$ on mixing with normal plasma prompted us to proceed with factor assays, which revealed markedly decreased factor X activity at 5\% (69-126\%) and mildly decreased factor V activity 63\% (81$160 \%)$. The patient had no apparent bleeding symptoms. The patient underwent autologous peripheral blood stem cell transplantation and achieved complete hematological remission. Follow-up coagulation tests revealed improvement of prolonged PT/aPTT (PT, 1.77 INR and aPTT, 52.5 sec) and normalization of factor V activity (136\%). However, factor X activity was still decreased at $12 \%$. Despite the improvement of coagulopathy, the patient experienced bleeding diathesis during the follow up for chronic kidney disease.

\section{Patient 2}

A 67-yr-old man with dyspnea was diagnosed with cardiac amyloidosis. Monoclonal immunoglobulins of IgG/ kappa type were detected in the serum and urine, and bone marrow analysis showed an increase of monoclonal plasma cells. Coagulation tests showed prolongation of both PT (1.63 INR) and aPTT (50.3 sec), which were corrected on mixing with normal plasma. Thrombin time test was not performed. Factor assays revealed a significant decrease of factor X activity at $17 \%$. Other coagulation factor activities were not decreased. He had no apparent bleeding manifestations. He received chemotherapy, and follow-up coagulation tests showed a normalized aPTT, but the PT was still prolonged (1.64 INR). Follow up for factor X activity was not performed.

\section{DISCUSSION}

Acquired factor deficiency with or without bleeding symptoms is not infrequent in $\mathrm{AL}$, whereas it is rare in other types of amyloidosis. Specific coagulation factor deficiencies in $\mathrm{AL}$ have long been recognized and have been explained by the adsorption of coagulation factors to amyloid fibrils. Evidence showing the interaction of amyloidogenic light chains with coagulation factors and anecdotal reports of improved hemostasis after removal of amyloidotic spleen support the fact that coagulation factors bind to the amyloid fibrils [5]. Both isolated coagulation factor deficiency and combined deficiencies have been reported. Factor X deficiency has been described as the most common acquired coagulation factor deficiency, affecting up to one-third of patients with AL. Deficiencies of other coagulation factors such as II, V, VII, and IX have also been reported [5-7]. According to a previous study that evaluated a total of 368 patients with AL, 32 patients had a factor $\mathrm{X}$ activity below $50 \%$ of normal. Eighteen of these patients (56\%) had bleeding complications, which were more severe in the 12 patients with factor X activity below 25\% of normal [7]. The 2 patients with acquired factor $\mathrm{X}$ deficiency from AL described in the present report had no bleeding symptoms, even with the very low level of factor X activity (5\%) in Patient 1 . A review of the literature revealed a single case report on acquired factor X deficiency in AL patients in Korea [9]. Kim et al. [9] reported factor $X$ deficiency in a patient with AL and nephrotic syndrome. The patient had mildly decreased factor X activity of $49 \%$ (70-120\%), prolonged PT of 1.32 INR and upper normal aPTT of $39.4 \mathrm{sec}$ (32-41.2 sec). Despite normal aPTT, mildly prolonged PT, and slightly decreased factor X activity, he had bleeding tendency and symptoms such as petechiae.

Previous studies reported that high-dose chemotherapy followed by autologous stem cell transplantation led to complete remission and normalization of the factor $\mathrm{X}$ level $[7,10,11]$. Patient 1 achieved complete remission after chemotherapy and autologous peripheral blood stem cell transplantation. The patient showed improvement of prolonged PT and APTT (2.51 to 1.77 INR and 75.1 to $52.5 \mathrm{sec}$, respectively). However, factor X activity was still significantly decreased (12\%), and the patient developed bleeding diathesis during the course of treatment. Indeed, it was reported that the baseline factor $\mathrm{X}$ level was not predictive of bleeding risk, and optimal management of factor $\mathrm{X}$ deficiency in $\mathrm{AL}$ is still elusive [12]. The findings in the previously reported patient [9] and the 2 patients described in the present report demonstrate the heterogeneous clinical and laboratory manifestations of factor X deficiency in Korean patients with AL.

To the best of our knowledge, this is only the second report of factor X deficiency in association with AL in Korea. Further prospective studies involving multiple institutions are needed to investigate the epidemiology and clinical implications of acquired factor X deficiency in Korean patients with AL. Appropriate coagulation workup should be conducted in patients with AL with prolonged coagulation times, and further studies are needed to obtain laboratory and clinical data to delineate the frequency and clinical implications of acquired coagulopathy in Korean patients with AL.

\section{Authors' Disclosures of Potential Conflicts of Interest}

No potential conflict of interest relevant to this article was reported. 


\section{REFERENCES}

1. Merlini G and Bellotti V. Molecular mechanisms of amyloidosis. N Engl J Med 2003;349:583-96.

2. Falk RH, Comenzo RL, Skinner M. The systemic amyloidoses. N Engl J Med 1997;337:898-909.

3. Enjeti AK, Walsh M, Seldon M. Spontaneous major bleeding in acquired factor $\mathrm{X}$ deficiency secondary to AL-amyloidosis. Haemophilia 2005;11:535-8.

4. Gamba G, Montani N, Anesi E, Palladini G, Capezzera M, Soldavini $\mathrm{E}$, et al. Clotting alterations in primary systemic amyloidosis. Haematologica 2000;85:289-92.

5. Mumford AD, O’Donnell J, Gillmore JD, Manning RA, Hawkins PN, Laffan M. Bleeding symptoms and coagulation abnormalities in 337 patients with AL-amyloidosis. Br J Haematol 2000;110:45460.

6. Sucker C, Hetzel GR, Grabensee B, Stockschlaeder M, Scharf RE. Amyloidosis and bleeding: pathophysiology, diagnosis, and therapy. Am J Kidney Dis 2006;47:947-55.

7. Choufani EB, Sanchorawala V, Ernst T, Quillen K, Skinner M, Wright DG, et al. Acquired factor $\mathrm{X}$ deficiency in patients with amyloid light-chain amyloidosis: incidence, bleeding manifestations, and response to high-dose chemotherapy. Blood 2001;97: 1885-7.

8. Girmann G, Wilker D, Stadie H, Scheurlen PG. Acquired isolated factor X deficiency associated with systemic amyloidosis. Case report and review of literature. Klin Wochenschr 1980;58:859-62.

9. Kim MY, Kwak SY, Kim KH, Lee JI, Ha YE, Kim DJ, et al. A case of primary amyloidosis with nephrotic syndrome and factor X deficiency. Korean J Nephrol 2008;27:133-6.

10. Adam Z, Matýková M, Krejcí M, Pour L, Kissová J, Slechtová M, et al. A patient with $\mathrm{AL}$ amyloidosis and severe factor $\mathrm{X}$ deficiency has been in complete haematological remission with normal factor $\mathrm{X}$ activity for 7 years following high-dose chemotherapy. A case study and literature review. Vnitr Lek 2010;56:67-78.

11. Breems DA, Sonneveld P, de Man RA, Leebeek FW. Successful treatment of systemic amyloidosis with hepatic involvement and factor X deficiency by high dose melphalan chemotherapy and autologous stem cell reinfusion. Eur J Haematol 2004;72:181-5.

12. Thompson CA, Kyle R, Gertz M, Heit J, Pruthi R, Pardanani A. Systemic AL amyloidosis with acquired factor X deficiency: a study of perioperative bleeding risk and treatment outcomes in $60 \mathrm{pa}-$ tients. Am J Hematol 2010;85:171-3. 